\title{
Levels and Health Risk Assessment of Heavy Metals in Soil, Water, and Vegetables of Dar es Salaam, Tanzania
}

\author{
David Sylvester Kacholi $\mathbb{B D}^{1}$ and Minati Sahu ${ }^{2}$ \\ ${ }^{1}$ Department of Biological Sciences, Dar es Salaam University College of Education, P.O. Box 2329, Dar es Salaam, Tanzania \\ ${ }^{2}$ Department of Chemistry, Dar es Salaam University College of Education, P.O. Box 2329, Dar es Salaam, Tanzania \\ Correspondence should be addressed to David Sylvester Kacholi; kacholi78@yahoo.com
}

Received 18 October 2017; Accepted 4 January 2018; Published 31 January 2018

Academic Editor: Qizhen Du

Copyright (c) 2018 David Sylvester Kacholi and Minati Sahu. This is an open access article distributed under the Creative Commons Attribution License, which permits unrestricted use, distribution, and reproduction in any medium, provided the original work is properly cited.

\begin{abstract}
This study assesses heavy metals' levels in water, soil, and vegetables (Ipomoea batatas (Matembele), Amaranthus hybridus (Mchicha), Abelmoschus esculentus (Bamia), and Solanum melongena (Bilinganya)) from the Changombe police garden located in Temeke district, Tanzania. Also, it examines potential health risks from consumption of the vegetables. The samples of soils, water, and vegetables were randomly collected, processed, and analyzed for heavy metals using Atomic Absorption Spectrophotometry. The heavy metals' levels in soil, water, and vegetables were in the order of $\mathrm{Fe}>\mathrm{Zn}>\mathrm{Pb}>\mathrm{Cu}$. Among the vegetables, I. batatas had highest heavy metal content followed by A. hybridus, S. melongena, and A. esculentus. The average daily intake for $\mathrm{Pb}$ $(63 \mathrm{mg} /$ person/day) was above the permissible maximum tolerable daily intake of $0.21 \mathrm{mg} /$ person/day endorsed by WHO/FAO. Hazard quotient of $\mathrm{Pb}$ for I. batatas (7.12) and A. hybridus (2.46) as well as the hazard indices of I. batatas (7.99) and A. hybridus (2.88) exceeded unity, signifying presence of health risks from consumption of the vegetables. This study recommends regular monitoring of heavy metals in soils, water, and foodstuffs to prevent excessive accrual in food chain.
\end{abstract}

\section{Introduction}

Heavy metals pollution is a menace to our environment as they are foremost contaminating agents of our food supply, especially vegetables [1]. Vegetables get contaminated by absorbing heavy metals from polluted air, soil, and water $[2,3]$. Heavy metals pollution in soil and water has a lot of adverse effects and thus is of great concern to the public health, agricultural production, and environmental health [4-7]. The soil pollution is mainly due to disposal of industrial and urban wastes as well as usage of agrochemicals [8-10], while water pollution is primarily caused by industrial wastes, sewage disposal, petroleum contamination, and agricultural drainage water [11-13]. Many growing areas in the developing countries are vulnerable to air pollution due to the fact that heavy metals containing aerosols are normally deposited on soil surface and get absorbed by vegetables or sometimes get deposited on plant leaves [14]. The uptake of heavy metals by the plants from the soil depends on different factors, including application of agrochemicals, solubility of heavy metals, soil $\mathrm{pH}$, soil type, and plant species $[15,16]$. Leafy vegetables accrue higher amounts of heavy metals in roots and leaves than stems and fruits [17-19]. The heavy metals at exceedingly higher concentrations than the required physiological demand of vegetables can cause lethal effect in them as well as human health through food chain $[4,20]$.

Vegetables constitute the most important daily diets in many of the households globally [21, 22]. However, the consumption of leafy vegetables is reported to increase in the urban community $[23,24]$; various researches revealed heavy metals like $\mathrm{Cu}, \mathrm{Zn}, \mathrm{Fe}, \mathrm{Pb}, \mathrm{Cd}, \mathrm{Mn}, \mathrm{Hg}$, and $\mathrm{Cr}$ to be significant contaminants of vegetables in urban agriculture $[1,2,18,24]$. Heavy metals like $\mathrm{Cu}, \mathrm{Zn}$, and $\mathrm{Fe}$ play a significant role in plant physiology but heavy metals such as $\mathrm{Pb}, \mathrm{Cd}, \mathrm{Cr}$, and $\mathrm{Hg}$ are exceptionally toxic and dangerous environmental pollutants $[8,10]$. A number of studies have shown that some common vegetables including Amaranthus species are proficient of accruing high heavy metals levels from contaminated irrigating water or growing soil $[25,26]$. 
TABLE 1: Description of the collected and analyzed vegetable samples.

\begin{tabular}{lccc}
\hline Common name & Local name & Scientific name & Edible parts \\
\hline Potato leaves & Matembele & Ipomoea batatas (L.) Lam. & leaf \\
African spinach & Mchicha & Amaranthus hybridus L. & leaf \\
Lady's finger & Bamia & Abelmoschus esculentus L. & fruit \\
Brinjal & Bilinganya & Solanum melongena L. & fruit \\
\hline
\end{tabular}

The consumption of vegetables is the main route of heavy metal toxicity to humans [27]. The ingestion of heavy metal contaminated vegetables may lead to various long-term lingering diseases; for instance, continuous exposure of $\mathrm{Cd}$ can cause pulmonary effects like emphysema, bronchiolitis, and alveolitis [28], while short-term exposure of Cd can cause renal effects [29]. The chronic buildup of heavy metals in the liver and kidney of humans results in disruption of many biochemical processes, which leads to nervous, kidney, cardiovascular, and bone diseases [30], while high $\mathrm{Zn}$ content may cause growth and reproduction impairment [31]. Lead toxicity causes dysfunction of kidney, reproductive and cardiovascular systems, joints problems, lessening in haemoglobin formation, and enduring impairment to the central and peripheral nervous systems [32].

The Changombe police garden is found in Changombe ward in Temeke district, Dar es Salaam region, Tanzania. The garden is located along the heavy traffic road of Mandela, where the environment is severely polluted with heavy metal from car exhaust. Increased urbanization and industrialization have caused amplified traffic activities in and around the ward, which consequently contributed to considerable accumulations of heavy metals in roadside environments. Hence, atmospheric deposition of toxic metals on vegetable surfaces can occur during vegetable production, transport, and marketing. Also, the heavy metals in the Changombe police garden may also get contaminated through irrigating waters as the water or while farmers wash them with polluted water before taking them to the markets. Therefore, the present study assesses heavy metals' levels $(\mathrm{Cu}, \mathrm{Zn}, \mathrm{Fe}$, and $\mathrm{Pb}$ ) in growing soil, irrigating water, and four popularly consumed vegetables, Amaranthus hybridus, Ipomoea batatas, Solanum melongena, and Abelmoschus esculentus, from the Changombe police garden. It also calculates the soil-plant transfer coefficients of heavy metals for each vegetable, heavy metal average daily intake rate, hazard quotient (HQ), and hazard index (HI). The last two indices help in assessing potential human health risk that can occur due to consumption of the vegetables. The study hypothesizes that heavy metals' levels are above established standards by WHO/FAO in all the studied compartments.

\section{Experimental}

2.1. Study Site and Sample Collection. Changombe police garden is located in Changombe ward in Temeke municipality in Dar es Salaam (Figure 1). The area is experiencing tropical climatic conditions due to its proximity to equator and Indian Ocean. The annual rainfall is approximately
$1,100 \mathrm{~mm}$, while the average annual temperature is approximately $25.9^{\circ} \mathrm{C}$. Urban agriculture in the municipality is well done in open spaces, mainly those situated along roads, between settlements, along railway lines, near industries, and along rivers [26]. The Changombe police garden is an open space located along the heavy traffic junction of Mandela road and Changombe road. The ward is one of the high income areas in the municipality as it owns many industries. Mandela road is mainly used to transport goods from Dar es Salaam port to up-country and outside the country.

Samples of soil, irrigating water, and edible portion of the four popularly consumed vegetables, namely, I. batatas, A. hybridus, $S$. melongena, and A. esculentus were collected from the Changombe police garden. All samples were randomly collected from the garden. The details of vegetable samples collected from the study site are shown in Table 1. Soil samples were collected up $15 \mathrm{~cm}$ depth around the garden. The collected soil and vegetable samples were put into clean polythene bags and labelled, while water samples were put in previously rinsed and dried bottles; thereafter, all the samples were brought to the Chemistry Laboratory of Dar es Salaam University College of Education (DUCE) for preparation and subsequently to the Chemistry Department of the University of Dar es Salaam (UDSM) for spectrophotometry analysis.

\subsection{Sample Preparation and Analysis}

2.2.1. Vegetables. The collected vegetable samples were washed using tap water and then with distilled water to eliminate dusts, pesticides, fertilizers, mud, and any airborne pollutant that may be present. The samples were dried at room temperature to remove moisture; afterwards, they were sliced using stainless steel knife, weighed, and oven-dried at $80^{\circ} \mathrm{C}$ for 72 hours to a constant weight. The oven-dried samples were then powdered and sieved through a mesh of $2 \mathrm{~mm}$ size. Thereafter, the samples were put in crucibles and kept in desiccators before placing them in a muffle furnace and ashed for 12 hours at $450^{\circ} \mathrm{C}$. The ashed sampled were then digested following the analytical procedures reported in Sahu and Kacholi's work [26].

2.2.2. Soil. The soil samples collected from the garden were thoroughly mixed to form a composite sample; then, the samples were oven-dried at $105^{\circ} \mathrm{C}$ for six hours until constant weight was attained. The oven-dried samples were then crushed and sieved through $2.0 \mathrm{~mm}$ wire mesh. Afterwards, thorough digestion of the representative samples was done. For each sample, $1 \mathrm{~g}$ was digested in $10 \mathrm{~mL}$ of $1: 1 \mathrm{HNO}_{3}$ and heated to $95^{\circ} \mathrm{C}$ to dry and thereafter refluxed for 10 minutes 


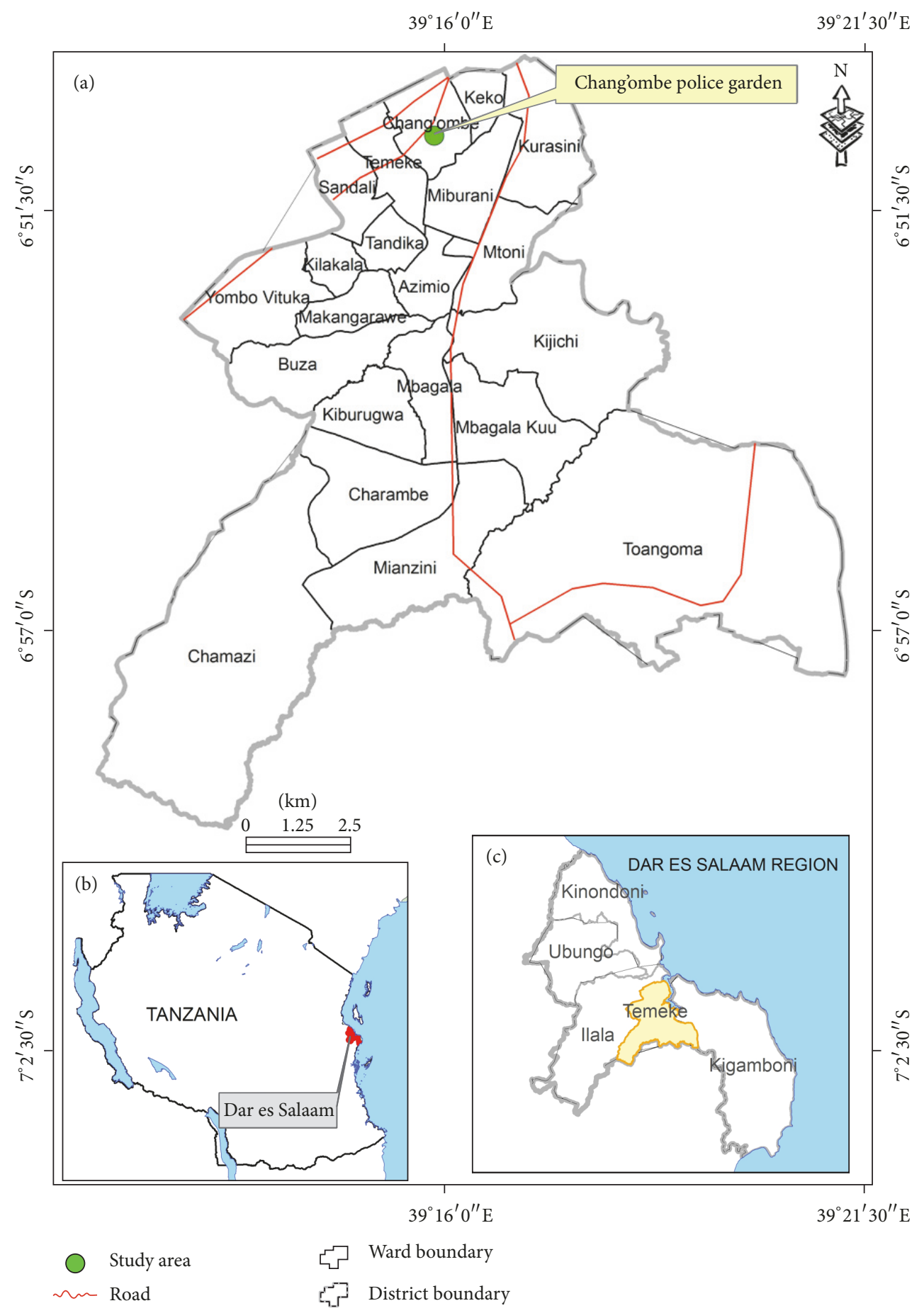

FIGURE 1: (a) The location of the study area in Temeke municipality; (b) location of Dar es Salaam region in Tanzania; and (c) the location of Temeke district in Dar es Salaam region.

without boiling. After cooling, $5 \mathrm{~mL}$ of concentrated $\mathrm{HNO}_{3}$ was once again added and refluxed for 30 minutes till brown fumes were produced. The process of adding $5 \mathrm{~mL}$ of concentrated $\mathrm{HNO}_{3}$ was repeated over and over till white fumes appeared. The solution was vaporized to about 5 on mantle set at $95^{\circ} \mathrm{C}$ with a watch glass over it. After cooling the resulting sample, $2 \mathrm{~mL}$ of $\mathrm{H}_{2} \mathrm{O}$ and $3 \mathrm{~mL}$ of $30 \% \mathrm{H}_{2} \mathrm{O}_{2}$ were added and the solution was placed on the heating mantle to start the oxidation of peroxide until effervescence subsided. The vessel was cooled and the acid-peroxide digestate heated to about $5 \mathrm{~mL}$ at $95^{\circ} \mathrm{C}$. Later, addition of $10 \mathrm{~mL}$ concentrated $\mathrm{HCl}$ to the sample digest was done and the solution was placed on the heating source and refluxed for 15 minutes at $95^{\circ} \mathrm{C}$. Finally, the digestate was filtered and the filtrate collected for analysis of 
heavy metals in the Atomic Absorption Spectrophotometer (AAS, Perkin Elmer 2380). The AAS was fitted with specific lamp of a particular heavy metal, while the other conditions were the same as explained by Welz and Sperling [33].

2.2.3. Water. The determination of heavy metals was done by adding $2 \mathrm{~mL}$ of concentrated $\mathrm{HNO}_{3}$ and $5 \mathrm{~mL}$ of concentrated $\mathrm{HCl}$ to a $100 \mathrm{~mL}$ aliquot of collected water sample. The solution was covered with a watch glass and heated at $95^{\circ} \mathrm{C}$ till volume reduced to $15 \mathrm{~mL}$ before being allowed to cool. Thereafter, the final volume was adjusted to $100 \mathrm{~mL}$ with reagent water and replicates were processed on a routine basis to determine precision. The concentrations of $\mathrm{Cu}, \mathrm{Zn}, \mathrm{Fe}$, and $\mathrm{Pb}$ in the filtrate of water were estimated using the AAS.

2.2.4. Quality Assurance Analysis. Assessment of contamination and reliability of data was done as part of quality control measure. Blank samples were scrutinized after every three samples for the purpose of ensuring that obtained results are within the range. The levels of heavy metals were calculated based on a dry weight and all the examinations were replicated thrice. The standard reference materials (SRM) for every metal obtained from the Chemistry Lab (UDSM) were used to check for accuracy and precision of analysis of each metal.

2.3. Soil-Plant Transfer Coefficient (\%). The soil-plant transfer coefficient, also known as enrichment factor, enumerates comparative variations in heavy metals' bioavailability to plants. The coefficient depends on both soil and plant properties. The accrual of metals from soil to plant depends on factors like plant species absorption capacity, soil type, and a metal chemical form. The soil-transfer coefficient was calculated as ratio of a heavy metal in a plant (dry weight) to a total heavy metal concentration in the soil as shown in the following equation:

$$
\mathrm{TC}=\frac{C_{\text {plant }}}{C_{\text {soil }}} \times 100,
$$

where TC is transfer coefficient (\%), $C_{\text {plant }}$ is heavy metal concentration in vegetable tissue $(\mathrm{mg} / 100 \mathrm{~g})$, and $C_{\text {soil }}$ is metal concentration in soil ( $\mathrm{mg} / 100 \mathrm{~g}$ dry soil).

2.4. Average Daily Intake (ADI). The ADI of a heavy metal was calculated as a product of average vegetable daily consumption per person, percentage of dry weight of vegetables, and average heavy metal concentration per dry weight vegetable as shown in the following equation:

$$
\mathrm{ADI}=\mathrm{Av}_{\text {consumption }} \times \% \mathrm{DW}_{\text {vegetable }} \times C_{\text {heavy metal }},
$$

where ADI is average daily intake of heavy metal per person per day ( $\mathrm{mg} /$ person/day), $\mathrm{Av}_{\text {consumption }}$ is average daily consumption of vegetable per person per day (g/day), $\% \mathrm{DW}_{\text {vegetable }}$ is percentage of dry weight of vegetable $(\% \mathrm{DW}=[(100-\%$ moisture $) / 100])$, and $C_{\text {heavy metal }}$ is average heavy metal concentration of dry weight vegetable $(\mathrm{mg} / \mathrm{g})$. The average daily consumption of vegetables suggested by WHO guidelines in human diet is 300 to $350 \mathrm{~g}$ per person [34]. The mean of $325 \mathrm{~g} /$ person/day was used in calculating the ADI values in this paper. An average weight of person was considered to be $60 \mathrm{~kg}$ [35].

2.5. Hazard Quotient (HQ). Hazard quotient is a proportion of the probable exposure to an element/chemical and level at which no negative impacts are expected. When the quotient is $<1$, this means no potential health effects are expected from exposure, but when it is $>1$, it signifies that there are potential health risks due to exposure [37]. The HQ is calculated as a fraction of determined dose to the reference dose as shown in the following equation:

$$
\mathrm{HQ}=\frac{\mathrm{ADI}}{R_{f} D},
$$

where ADI is the average vegetables intake per day (mg/kg/day) and $R_{f} D$ is the oral reference dose of the metal (mg/kg/day). $R_{f} D$ is an approximation of daily tolerable exposure to which a person is expected to have without any significant risk of harmful effects during a lifespan. $R_{f} D$ for $\mathrm{Pb}, \mathrm{Zn}, \mathrm{Cu}$, and $\mathrm{Fe}$ is $0.004 \mathrm{mg} / \mathrm{kg} /$ day, $0.3 \mathrm{mg} / \mathrm{kg} / \mathrm{day}$, $0.04 \mathrm{mg} / \mathrm{kg} / \mathrm{day}$, and $0.7 \mathrm{mg} / \mathrm{kg} / \mathrm{day}$, respectively [36].

2.6. Hazard Index (HI). An exposure to more than one pollutant results in additive effects. Thus, hazard index (HI) is a vital index that assesses overall likely impacts that can be posed by exposure to more than one contaminant. When the $\mathrm{HI}$ is $>1$, this suggests that there are significant health effects from consuming pollutants contained in a foodstuff. The HI is calculated as an arithmetic sum of the hazard quotients for each pollutant as shown in the following equation:

$$
\begin{aligned}
\mathrm{HI} & =\sum_{i=1}^{4} \mathrm{HQ}=\left[\frac{\mathrm{ADI}_{\mathrm{Pb}} \times C_{\mathrm{hm} \mathrm{Pb}}}{R_{f} D_{\mathrm{Pb}}}+\frac{\mathrm{ADI}_{\mathrm{Zn}} \times C_{\mathrm{hm} \mathrm{Zn}}}{R_{f} D_{\mathrm{Zn}}}\right. \\
& \left.+\frac{\mathrm{ADI}_{\mathrm{Cu}} \times C_{\mathrm{hm} \mathrm{Cu}}}{R_{f} D_{\mathrm{Cu}}}+\frac{\mathrm{ADI}_{\mathrm{Fe}} \times C_{\mathrm{hm} \mathrm{Fe}}}{R_{f} D_{\mathrm{Fe}}}\right],
\end{aligned}
$$

where $\mathrm{HQ}$ is hazard quotient of a heavy metal, $\mathrm{ADI}$ is average daily intake of a heavy metal, $C_{\mathrm{hm}}$ is concentration of a heavy metal, and $R_{f} D$ is a reference dose of a heavy metal.

2.7. Statistical Analysis. Data were subjected to statistical analysis using the QED statistics software. The heavy metals' levels among the vegetables were compared using the OneWay Analysis of Variance (ANOVA) and the means were compared using Tukey's post hoc test at 5\% significance level.

\section{Results and Discussion}

3.1. Heavy Metals' Levels in Water and Soil. The heavy metals' levels in water were highest for Fe followed by $\mathrm{Zn}, \mathrm{Pb}$, and $\mathrm{Cu}$. The levels of heavy metals in water samples ranged from 0.99 to $1.26 \mathrm{mg} / \mathrm{l}$, from 0.35 to $1.19 \mathrm{mg} / \mathrm{l}$, from 0.46 to $0.55 \mathrm{mg} / \mathrm{l}$, and from 0.11 to $0.17 \mathrm{mg} / \mathrm{l}$ for $\mathrm{Fe}, \mathrm{Zn}, \mathrm{Pb}$, and $\mathrm{Cu}$, respectively. The concentrations of $\mathrm{Pb}$ and $\mathrm{Fe}$ were higher than the established standards, while those of $\mathrm{Zn}$ and $\mathrm{Cu}$ were lower (Table 2). The findings indicate that the irrigating water is polluted chiefly 
TABLE 2: Observed mean ( \pm standard deviation) of heavy metal levels in water and soil $(n=6)$.

\begin{tabular}{|c|c|c|c|c|}
\hline & $\mathrm{Pb}$ & $\mathrm{Zn}$ & $\mathrm{Cu}$ & $\mathrm{Fe}$ \\
\hline \multicolumn{5}{|l|}{ Water (mg/l) } \\
\hline Observed & $0.5(0.00)$ & $0.8(0.04)$ & $0.1(0.00)$ & $1.1(0.01)$ \\
\hline Standard & 0.01 & 5 & 2 & 0.3 \\
\hline \multicolumn{5}{|c|}{ Soil (mg/100 g dry soil) } \\
\hline Observed & $227.4(2.9)$ & $307.1(1.2)$ & $17.8(2.3)$ & $2796.6(36.5)$ \\
\hline Standard & $1.0-7.0^{\mathrm{a}}$ & $5.0-10.0^{\mathrm{b}}$ & $0.6-6.0^{\mathrm{a}}$ & $15.0^{\mathrm{c}}$ \\
\hline
\end{tabular}

TABLE 3: Percentage of moisture content and mean ( \pm standard deviation) of heavy metal levels $(\mathrm{mg} / 100 \mathrm{~g})$ in the four vegetables $(n=6)$.

\begin{tabular}{lccccc}
\hline Scientific name & \% of moisture content & $\mathrm{Pb}$ & $\mathrm{Zn}$ & $\mathrm{Cu}$ & $\mathrm{Fe}$ \\
\hline I. batatas & 78.59 & $2.46(0.36)^{\mathrm{a}}$ & $8.84(1.21)^{\mathrm{a}}$ & $1.04(0.16)^{\mathrm{a}}$ & $13.64(1.92)^{\mathrm{a}}$ \\
A. hybridus & 86.96 & $1.39(0.06)^{\mathrm{b}}$ & $5.76(0.26)^{\mathrm{b}}$ & $0.98(0.02)^{\mathrm{a}}$ & $10.61(0.40)^{\mathrm{b}}$ \\
A. esculentus & 87.85 & $0.33(0.08)^{\mathrm{c}}$ & $2.64(0.17)^{\mathrm{c}}$ & $0.68(0.01)^{\mathrm{b}}$ & $4.84(0.37)^{\mathrm{c}}$ \\
S. melongena & 91.04 & $0.32(0.05)^{\mathrm{c}}$ & $10.29(0.64)^{\mathrm{d}}$ & $0.55(0.10)^{\mathrm{b}}$ & $5.65(0.44)^{\mathrm{c}}$ \\
${ }^{\dagger}$ FAO/WHO & & 0.03 & 6.0 & 4.0 & 42.5 \\
\hline
\end{tabular}

Different letters down columns within the same heavy metal represent significant differences at $p<0.05 ;{ }^{\dagger} \mathrm{FAO} / \mathrm{WHO}$ maximum permissible limits $[35,36]$.

by $\mathrm{Pb}$ and $\mathrm{Fe}$. The possible sources of heavy metals like $\mathrm{Pb}$ and $\mathrm{Cu}$ could be road runoff and atmospheric deposition $[38,39]$. This is due to the fact that the used ponds are about $20 \mathrm{~m}$ from the Mandela road, which is round the clock a busy road with heavy traffic.

The levels of heavy metals in the growing soil were highest for $\mathrm{Fe}$ followed by $\mathrm{Zn}, \mathrm{Pb}$, and $\mathrm{Cu}$. In the soil samples, the Fe content ranged from 2760.1 to $2833.07 \mathrm{mg} / 100 \mathrm{~g}$ dry soil, $\mathrm{Cu}$ ranged from 15.5 to $20.13 \mathrm{mg} / 100 \mathrm{~g}$, $\mathrm{Zn}$ ranged from 305.95 to $308.25 \mathrm{mg} / 100 \mathrm{~g}$, and $\mathrm{Pb}$ ranged from 224.48 to $230.39 \mathrm{mg} / 100 \mathrm{~g}$. The observed levels in soil samples were higher than the permissible limits in agricultural soils (Table 2). Thus, these findings suggest that the studied soil sample is severely contaminated by the referred heavy metals. The high observed Fe levels could be attributed to the nature of the parental material of soils in the study site. Also, Fe and $\mathrm{Zn}$ could be emanating from phosphate fertilizers, waste water disposal, organic wastes dumping, use of sludge, and burning of the fossil fuels in the area [38], while $\mathrm{Pb}$ and $\mathrm{Cu}$ are stemming from nearby traffic activities and use of agrochemicals, respectively [39]. Thus, from the results, it is concluded that the soil of the study area was highly polluted by the four investigated elements.

3.2. Heavy Metal Levels in Vegetables. Heavy metals' levels revealed significant variations in the four studied vegetables (Table 3). The levels ranged from 0.23 to $2.92 \mathrm{mg} / 100 \mathrm{~g}$ for $\mathrm{Pb}$, from 2.44 to $11.11 \mathrm{mg} / 100 \mathrm{~g}$ for $\mathrm{Zn}$, from 0.46 to $1.24 \mathrm{mg} / 100 \mathrm{~g}$ for $\mathrm{Cu}$, and from 4.39 to $16.12 \mathrm{mg} / 100 \mathrm{~g}$ for Fe. The comparison among vegetables revealed that $\mathrm{Pb}$ and $\mathrm{Cu}$ concentrations decreased in the order of I. batatas $>A$. hybridus $>$ A. esculentus $>$ S. melongena, Zn concentrations decreased in the order of $S$. melongena $>I$. batatas $>A$. hybridus $>$ A. esculentus, and Fe levels decreased in the order of I. batatas > A. hybridus > S. melongena, > A. esculentus. Of all the heavy metals, Fe levels were found to be highest in I. batatas, A. hybridus, and A. esculentus in comparison to other metals. The highest $\mathrm{Fe}$ concentration in vegetables was also observed in Changombe Mchicha area, Dar es Salaam [26]. This can be associated with the nature of the soil as it was found to have high Fe content (Table 2). The highest levels of $\mathrm{Zn}$ than $\mathrm{Pb}$ and $\mathrm{Cu}$ observed in the vegetables have been also observed in India and Bangladesh [38, 40]. The disparities in the heavy metals' levels may be attributed to differences in absorption capacities of the vegetables and their translocation within the plants [14, 40]. The levels of $\mathrm{Pb}$ in all vegetables as well as $\mathrm{Zn}$ in $I$. batatas and $S$. melongena were greater than the $\mathrm{WHO} / \mathrm{FAO}$ recommended levels of contaminants in food products [41]. Although $\mathrm{Zn}$ is considered to be essential element for numerous bioactivities in the human body, its high level in the vegetables can affect consumer health negatively $[30,31,42]$. The higher levels of heavy metals in the vegetables could also be attributed to the location of the garden, which is situated along the hectic road traffic. Heavy metals like $\mathrm{Cu}$ and $\mathrm{Zn}$ in the garden could be ascribed to agricultural products that were added to the soil, while $\mathrm{Pb}$ is a contaminant that is known to emanate from traffic activities, such as fuel combustion, lubricating oil, tyre and brake wear, road abrasion, and road runoff, which in one way or the other can impact roadside grown vegetables [39].

3.3. Soil-Plant Transfer Coefficients. Soil-plant transfer coefficient is an imperative component of human exposure to heavy metals through food chain as it describes movement of contaminants from soil to plants $[38,40]$. The findings in Table 4 indicate that all the four vegetables had high $\mathrm{Cu}$ transfer coefficients followed by $\mathrm{Zn}, \mathrm{Cu}$, and $\mathrm{Fe}$. Among the vegetables, I. batatas had highest transfer coefficients for $\mathrm{Pb}$, $\mathrm{Cu}$, and $\mathrm{Fe}$, while $S$. melongena had higher transfer coefficient for Zn. A. esculentus and S. melongena had lowermost transfer coefficients for $\mathrm{Zn}$ and $\mathrm{Fe}$ as well as $\mathrm{Pb}$ and $\mathrm{Cu}$, respectively. The average soil-plant transfer coefficients for the vegetable 
TABLE 4: Soil-vegetable transfer coefficients (\%) of heavy metals.

\begin{tabular}{lccccc}
\hline Scientific name & $\mathrm{Pb}$ & $\mathrm{Zn}$ & $\mathrm{Cu}$ & $\mathrm{Fe}$ & Efficacy \\
\hline I. batatas & 1.08 & 2.88 & 5.82 & 0.49 & 2.57 \\
A. hybridus & 0.61 & 1.87 & 5.48 & 0.38 & 2.09 \\
A. esculentus & 0.15 & 0.86 & 3.84 & 0.17 & 1.26 \\
S. melongena & 0.14 & 3.35 & 3.07 & 0.20 & 1.69 \\
Average & 0.50 & 2.24 & 4.55 & 0.31 & \\
\hline
\end{tabular}

are in order of $\mathrm{Cu}(4.55)>\mathrm{Zn}(2.24)>\mathrm{Pb}(0.50)>\mathrm{Fe}(0.31)$, while the efficacy in absorbing heavy metals is in order of I. batatas (2.57) > A. hybridus (2.09) > S. melongena (1.69) $>$ A. esculentus (1.26). These findings indicate that $\mathrm{Cu}$ has higher transferability, while I. batatas is having high absorbing capability followed by A. hybridus. Moreover, the transfer coefficient depends on bioavailability of a metal itself, levels of metal in soil, chemical form of a metal, plant uptake capabilities, and plant species growth rate [15]. From the findings, the soil-plant transfer coefficients are directly related to the observed levels of heavy metals. The highest coefficient value for $\mathrm{Cu}$ and $\mathrm{Zn}$ might be due to higher mobility of these heavy metals with a natural occurrence in soil [43] and the lower retention of them in the soil than other cations [44]. The higher concentrations of these heavy metals could be due to increased contamination through waste water irrigation, solid waste disposal and sludge applications, solid waste combustion, agrochemicals and vehicular exhausted [27].

3.4. Average Daily Intake (ADI) of Heavy Metals through Vegetables. Estimating heavy metal exposure level is indispensable in determining organism health risk [3]. Various routes of exposure to humans do exist, yet the most significant is the food chain. The ADI of heavy metals (Table 5) shows that $\mathrm{Pb}$ is consumed above the permitted maximum tolerable daily intake (PMTDI) endorsed by WHO/FAO of $0.21 \mathrm{mg} /$ person per day, whereas the rest were below permissible limits. The $\mathrm{ADI}$ for $\mathrm{Pb}$ was estimated to be $0.63 \mathrm{mg} /$ person/day, which represents $7.4 \%$ of the total intake of the heavy metals. The order of contribution for the $\mathrm{Pb}$ intake is as follows: I. batatas $>$ A. hybridus $>$ A. esculentus $>$ S. melongena. The last two did not differ appreciably in their $\mathrm{Pb}$ content and contributions. The high observed $\mathrm{Pb}$ content in vegetables threatens human health. The high level of $\mathrm{Pb}$ is attributed to the roadside location of the garden and the transitory heavy traffic. The $\mathrm{Pb}$ toxicity affects many organs in humans, such as liver, kidney, lungs, and spleen, causing severe biochemical defects. High average daily intake of $\mathrm{Pb}$ has been also reported in Dar es Salaam, Tanzania [23].

Zinc is an important metal in human body as it plays a vital role in normal growth and development. Higher intake of $\mathrm{Zn}$ can result in suppression of $\mathrm{Cu}$ and $\mathrm{Fe}$ absorption, gastrointestinal irritation, and interference of physiological processes [26]. Deficiency of $\mathrm{Zn}$ results from insufficient dietary intake, reduced absorption, excessive excretion, or inherited defects in zinc metabolism [42]. The estimated daily intake of $\mathrm{Zn}$ is $3.16 \mathrm{mg} /$ person/day, which represents $36.8 \%$ of the total intake of the heavy metals. The order of contribution

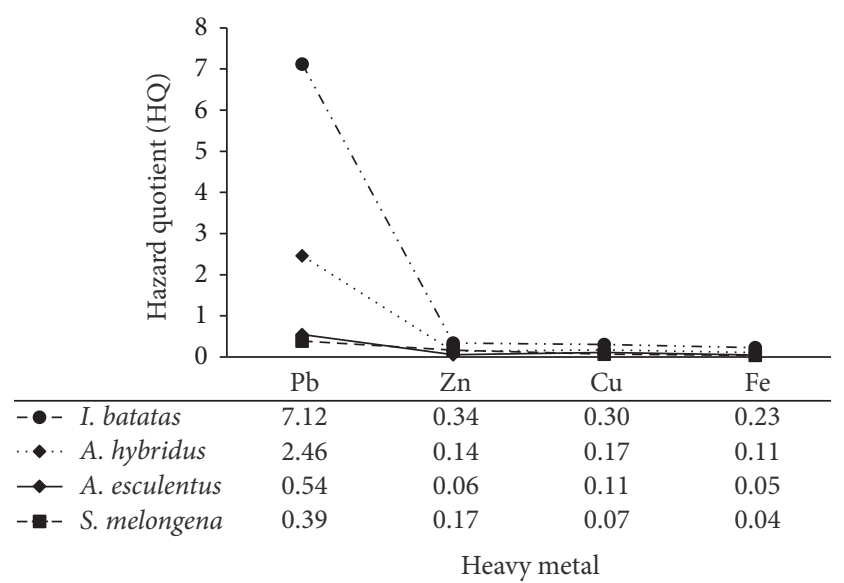

FIGURE 2: Hazard quotient (HQ) of individual metal for the studied vegetables.

for $\mathrm{Zn}$ intake is as follows: I. batatas $>$ A. hybridus $>A$. esculentus $>$ S. melongena.

Copper is a vital element in the human body as it is responsible for upholding central nervous system health, proper working of the metabolic processes, pigmentation, and prevention of anaemia [43]. Continuing low $\mathrm{Cu}$ levels have damaging effects to humans due to the nature of the role copper plays [10]. People suffering from Wilson's disease are at great risk for health effects when overexposed to copper [30]. When $\mathrm{Cu}$ exceeds safe limits in the human body, it possesses health hazards like hypertension, sporadic fever, coma, anaemia, and liver and kidney damage as well as stomach and intestine irritation [37]. The average daily intake of Cu is estimated to be $0.88 \mathrm{mg} / \mathrm{person} /$ day, which represents $4.6 \%$ of the total intake of the heavy metals. The order of contribution for the $\mathrm{Cu}$ intake is I. batatas $>$ A. hybridus $>$ A. esculentus $>$ S. melongena.

The Fe average daily intake was estimated to be $4.39 \mathrm{mg} /$ person/day, which represents $51.2 \%$ of the total intake of the heavy metals. The order of contribution for the Fe intake is $I$. batatas $>$ A. hybridus $>$ A. esculentus $>$ S. melongena. Actually, the observed levels were below the PMTDI recommended by WHO. Excessive Fe in human body can result in siderosis in liver, pancreas thyroid, pituitary, adrenal glands, and heart depending on the chemical form. It is also reported that doses with $\mathrm{Fe}$ content larger than $20 \mathrm{mg} /$ person/day may cause stomach upset, constipation, and blackened stools [36].

3.5. Hazard Quotient. The findings show that hazard quotient (HQ) values of all heavy metals were $<1$ in all the vegetables except for $\mathrm{Pb}$ in $I$. batatas and A. hybridus (Figure 2). When HQ exceeds one, this means there are potential health effects from exposure [45]. The high HQ for $\mathrm{Pb}$ observed in I. batatas (7.12) and A. hybridus (2.46) has significant carcinogenic health jeopardies to consumers, while for the rest of the vegetables, consumers are nearly free of the risks. High $\mathrm{HQ}$ for $\mathrm{Pb}$ was also reported in China and India [46, 47]. Although there was no apparent health risk to local population due to consumption of individual metal present in the vegetables (except for $\mathrm{Pb}$ in I. batatas and A. hybridus), the 
TABLE 5: Average daily intake ( \pm standard deviation) of heavy metals (mg/person/day).

\begin{tabular}{lcccc}
\hline Scientific name & $\mathrm{Pb}$ & $\mathrm{Zn}$ & $\mathrm{Cu}$ & $\mathrm{Fe}$ \\
\hline I. batatas & $1.71(0.14)$ & $6.15(0.77)$ & $0.72(0.12)$ & $9.49(1.22)$ \\
A. hybridus & $0.59(0.03)$ & $2.44(0.10)$ & $0.41(0.01)$ & $4.50(0.15)$ \\
A. esculentus & $0.13(0.03)$ & $1.04(0.06)$ & $0.27(0.01)$ & $1.91(0.13)$ \\
S. melongena & $0.09(0.01)$ & $3.00(0.17)$ & $0.16(0.03)$ & $1.65(0.01)$ \\
Average & 0.63 & 3.16 & 0.39 & 4.39 \\
PMTDI & 0.21 & 15.0 & 2.0 & 15.0 \\
\hline
\end{tabular}

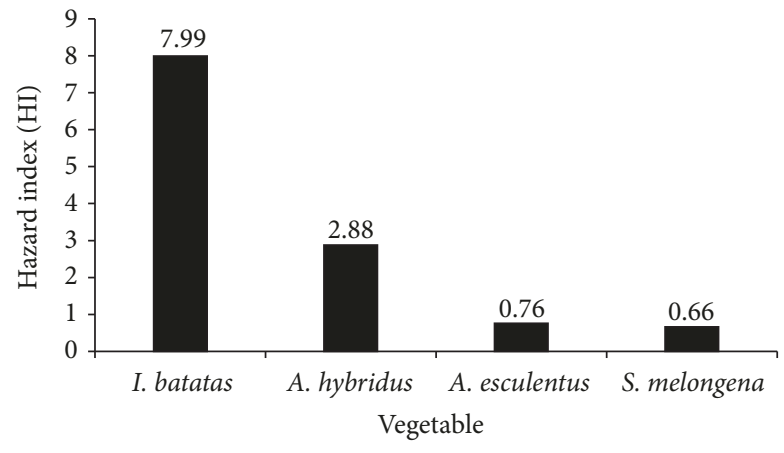

FIGURE 3: Hazard index (HI) for each studied vegetable.

potential risk could be multiplied when considering all the heavy metals together $[22,48]$. Hence, estimation of hazard index (HI), which takes care of the chemical mixtures, is very important in assessing multiple effects of the heavy metals.

3.6. Hazard Index (HI). The results in Figure 3 show that the highest HI was found in I. batatas (7.99) followed by $A$. hybridus (2.88) > A. esculentus (0.76) $>$ S. melongena (0.66). When the HI surpasses unity, this tells us that eating of the food can cause health effects [49-51]. For our case, consumption of $I$. batatas and A. hybridus by the locals is posing high risks to their health as their HI was greater than one. In all the studied vegetables, the total $\mathrm{HI}$ is dominated by $\mathrm{Pb}$ contribution, that is, $89 \%$ in the I. batatas, $86 \%$ in $A$. hybridus, $72 \%$ in A. esculentus, and 59\% in S. melongena.

\section{Conclusion and Recommendations}

In summary, the results revealed that $\mathrm{Pb}$ and $\mathrm{Fe}$ contents in irrigating water were higher than the agricultural water standards. In soil, all the heavy metals' levels were above the set standards for agricultural soils, while in vegetables, the mean concentrations of $\mathrm{Zn}$ and $\mathrm{Pb}$ were higher than the set standards. The findings on the average daily intake (ADI), hazard quotient (HQ), and hazard index (HI) revealed that consumption of I. batatas and A. hybridus could pose carcinogenic risks to human health due to high level of lead $(\mathrm{Pb})$, while consumption of $A$. esculentus and $S$. melongena is reasonably safe. I. batatas revealed highest transfer coefficients for $\mathrm{Pb}, \mathrm{Cu}$, and $\mathrm{Fe}$, while $\mathrm{S}$. melongena had higher transfer coefficient for $\mathrm{Zn}$. A. esculentus and S. melongena had least transfer coefficients for $\mathrm{Zn}$ and $\mathrm{Fe}$ as well as $\mathrm{Pb}$ and $\mathrm{Cu}$, respectively. No matter how low levels of heavy metals are present in vegetables, their presence is not desirable. Therefore, this study suggests the regular scrutiny of the heavy metals present in soil, irrigating water, and foodstuff to avoid extreme accrual in the food chain and thus elude human health risks. Consequently, this study encourages environmentalists, administrators, and public health workers to create public awareness to avoid the consumption of vegetables grown in contaminated soils, hence reducing health risks.

\section{Conflicts of Interest}

The authors declare that there are no conflicts of interest regarding the publication of this article.

\section{Acknowledgments}

The authors are deeply indebted to the staff of the Department of Chemistry of the University of Dar es Salaam (Mwalimu Julius Kambarage Nyerere Campus) and that of the Dar es Salaam University College of Education (DUCE) for their technical assistance during laboratory work.

\section{References}

[1] G. Chauhan and U. K. Chauhan, "Human health risk assessment of heavy metals via dietary intake of vegetables grown in wastewater irrigated area of Rewa, India," International Journal of Scientific Research and Publications, vol. 4, no. 9, pp. 1-9, 2014.

[2] R. K. Sharma, M. Agrawal, and F. M. Marshall, "Atmospheric deposition of heavy metals $(\mathrm{Cu}, \mathrm{Zn}, \mathrm{Cd}$ and $\mathrm{Pb})$ in Varanasi City, India," Environmental Modeling \& Assessment, vol. 142, no. 1-3, pp. 269-278, 2008.

[3] A. Singh, R. K. Sharma, M. Agrawal, and F. M. Marshall, "Risk assessment of heavy metal toxicity through contaminated vegetables from waste water irrigated area of Varanasi, India," Tropical Ecology, vol. 51, no. 2, pp. 375-387, 2010.

[4] R. A. Goyer, “Toxic and essential metal interactions," Annual Review of Nutrition, vol. 17, pp. 37-50, 1997.

[5] J. E. Fergusson, The Heavy Elements: Chemistry, Environmental Impact And Health Effects, Pergamin Press, Oxford, UK, 1990.

[6] J. J. Msaky and R. Calvet, "Adsorption behavior of copper and zinc in soils: Influence of $\mathrm{pH}$ on adsorption characteristics," Soil Science, vol. 150, no. 2, pp. 513-522, 1990.

[7] Q. Y. Ma, S. J. Traina, T. J. Logan, and J. A. Ryan, "Effects of Aqueous $\mathrm{Al}, \mathrm{Cd}, \mathrm{Cu}, \mathrm{Fe}(\mathrm{II}), \mathrm{Ni}$, and $\mathrm{Zn}$ on $\mathrm{Pb}$ Immobilization by Hydroxyapatite," Environmental Science \& Technology, vol. 28, no. 7, pp. 1219-1228, 1994.

[8] M. J. Buchauer, "Contamination of soil and vegetation near a zinc smelter by zinc, cadmium, copper, and lead," Environmental Science \& Technology, vol. 7, no. 2, pp. 131-135, 1973. 
[9] M. B. McBride, "Toxic metals in sewage sludge-amended soils: Has promotion of beneficial use discounted the risks?" Advances in Environmental Research, vol. 8, no. 1, pp. 5-19, 2003.

[10] D. Demirezen and A. Aksoy, "Heavy metal levels in vegetables in Turkey are within safe limits for $\mathrm{Cu}, \mathrm{Zn}, \mathrm{Ni}$ and exceeded for Cd and Pb," Journal of Food Quality, vol. 29, no. 3, pp. 252-265, 2006.

[11] I. R. Santos, E. V. Silva-Filho, C. E. G. R. Schaefer, M. R. Albuquerque-Filho, and L. S. Campos, "Heavy metal contamination in coastal sediments and soils near the Brazilian Antarctic Station, King George Island," Marine Pollution Bulletin, vol. 50, no. 2, pp. 185-194, 2005.

[12] R. A. Midrar-Ul-Haq, H. K. Khattak, M. S. Puno, K. S. Saif, and Memon., "Surface and ground water contamination in NWFP and Sindh provinces with respect to trace elements," International Journal of Agriculture and Biology, vol. 7, no. 2, pp. 214-217, 2005.

[13] M. Tariq, M. Ali, and Z. Shah, "Characteristics of industrial effluents and their possible impacts on quality of underground water," Soil Environment, vol. 25, no. 1, pp. 64-69, 2006.

[14] D. Voutsa, A. Grimanis, and C. Samara, "Trace elements in vegetables grown in an industrial area in relation to soil and air particulate matter," Environmental Pollution, vol. 94, no. 3, pp. 325-335, 1996.

[15] P. B. Tinker, "Levels, distribution and chemical forms of trace elements in food plants.", Philosophical Transactions of the Royal Society B: Biological Sciences, vol. 294, no. 1071, pp. 41-55, 1981.

[16] S. Lubben and D. Sauerbeck, "The uptake and distribution of heavy metals by spring wheat," Water, Air, \& Soil Pollution, vol. 57, no. 1, pp. 239-247, 1991.

[17] V. K. Sharma and B. D. Kansal, "Heavy metal contamination of soils and plants with sewage irrigation," Pollution. Research, vol. 4, pp. 86-91, 1986.

[18] S. Singh and M. Kumar, "Heavy metal load of soil, water and vegetables in peri-urban Delhi," Environmental Modeling \& Assessment, vol. 120, no. 1-3, pp. 79-91, 2006.

[19] B. Yargholi and A. Azimi, "Investigation of Cadmium absorption and accumulation in different parts of some vegetables," American-Eurasian Journal of Agricultural \& Environmental Sciences, vol. 3, no. 3, pp. 357-364, 2008.

[20] A. Waseem, J. Arshad, F. Iqbal, A. Sajjad, Z. Mehmood, and G. Murtaza, "Pollution Status of Pakistan: A Retrospective Review on Heavy Metal Contamination of Water, Soil, and Vegetables," BioMed Research International, vol. 2014, Article ID 813206, 29 pages, 2014.

[21] T. E. Bahemuka and E. B. Mubofu, "Heavy metals in edible green vegetables grown along the sites of the Sinza and Msimbazi rivers in Dar es Salaam, Tanzania," Food Chemistry, vol. 66, no. 1, pp. 63-66, 1999.

[22] S. Sinha, A. K. Gupta, K. Bhatt, K. Pandey, U. N. Rai, and K. P. Singh, "Distribution of metals in the edible plants grown at Jajmau, Kanpur (India) receiving treated tannery wastewater: Relation with physico-chemical properties of the soil," Environmental Modeling \& Assessment, vol. 115, no. 1-3, pp. 1-22, 2006.

[23] O. C. Othman, "Heavy metals in green vegetables and soils from vegetable gardens in Dar es Salaam, Tanzania," Tanzania Journal of Science, vol. 29, no. 1, pp. 37-48, 2001.

[24] A. A. Yusuf, T. A. Arowolo, and O. Bamgbose, "Cadmium, copper and nickel levels in vegetables from industrial and residential areas of Lagos City, Nigeria," Food and Chemical Toxicology, vol. 41, no. 3, pp. 375-378, 2003.
[25] R. K. Sharma, M. Agrawal, and F. Marshall, "Heavy metal contamination in vegetables grown in wastewater irrigated areas of Varanasi, India," Bulletin of Environmental Contamination and Toxicology, vol. 77, no. 2, pp. 312-318, 2006.

[26] M. Sahu and D. S. Kacholi, "Heavy metal levels in Amaranthus species from Changombe-Mchicha area in Temeke District, Dar es Salaam, Tanzania," Asian Journal of Chemistry, vol. 28, no. 5, pp. 1123-1126, 2016.

[27] M. Intawongse and J. R. Dean, "Uptake of heavy metals by vegetable plants grown on contaminated soil and their bioavailability in the human gastrointestinal tract," Food Additives \& Contaminants: Part A, vol. 23, no. 1, pp. 36-48, 2006.

[28] J. O. Duruibe, M. D. C. Ogwuegbu, and J. N. Egwurugwu, "Heavy metal pollution and human biotoxic effects," International Jopurnal of Physical Sciences, vol. 2, no. 5, pp. 112-118, 2007.

[29] R. A. Young, Toxicity Profiles: Toxicity Summary of Cadmium, Risk Assessment Information System, vol. 8, University of Tannessee, 2005, 2005. https://rais.ornl.gov/tox/profiles/cadmium .html.

[30] L. Järup, "Hazards of heavy metal contamination," British Medical Bulletin, vol. 68, no. 1, pp. 167-182, 2003.

[31] K. R. Nolan, "Copper toxicity syndrome," Journal of Orthomolecular Psychiatry, vol. 12, no. 4, pp. 270-282, 1983.

[32] M. O. C. Ogwuegbu and W. Muhanga, "Investigation of lead concentration in the blood of people in the copper belt province of Zambia," Journal of Environment, vol. 1, pp. 66-75, 2005.

[33] B. Welz and M. Sperling, Atomic Absorption Spectrometry, Wiley-VCH, Verlag GmbH, Weinheim, Germany, 3rd edition, 1999.

[34] Tech. Rep., "Evaluation of certain food additives and contaminants," Technical report series Geneva, 33rd Report of the joint FAO/WHO expert committee on food additives. World Health organization (WHO), Geneva, Switzerland, 1989.

[35] Tech. Rep., "Evaluation of certain food additives and contaminants," Technical report series Geneva, 41st Report of the joint FAO/WHO expert committee on food additives. World Health organization (WHO), Geneva, Switzerland, 1993.

[36] Tech. Rep., "Guidelines for the safe use of wastewater and food stuff" Report of the joint WHO/FAO Volume 2 no. 1, World Health Organization (WHO) and Food and Agriculture Organization (FAO), Geneva, Switzerland, 2013.

[37] G. M. A. Bermudez, R. Jasan, R. Plá, and M. L. Pignata, "Heavy metal and trace element concentrations in wheat grains: Assessment of potential non-carcinogenic health hazard through their consumption," Journal of Hazardous Materials, vol. 193, pp. 264271, 2011.

[38] R. C. Tasrina, A. Rowshon, A. M. R. Mustafizur, I. Rafiqul, and M. P. Ali, "Heavy metals contamination in vegetables and its growing soil," Journal of Environmental Analytical. Chemistry, vol. 2, no. 3, article 142, 2015.

[39] T. Kananke, J. Wansapala, and A. Gunaratne, "Heavy Metal Contamination in Green Leafy Vegetables Collected from Selected Market Sites of Piliyandala Area, Colombo District, Sri Lanka," American Journal of Food Science and Technology, vol. 2, no. 5, pp. 139-144, 2014.

[40] S. Gupta, V. Jena, S. Jena et al., "Assessment of heavy metal contents of green leafy vegetables," Croatian Journal of Food Science and Technology, vol. 5, no. 2, pp. 53-60, 2013.

[41] "Codex general standard for contaminants and toxins in foods," Joint FAO/WHO joint food standards programme, Codex Alimentarious commission, Rome, Italy, 1996. 
[42] I. Narin, M. Tuzen, H. Sari, and M. Soylak, "Heavy metal content of potato and corn chips from Turkey," Bulletin of Environmental Contamination and Toxicology, vol. 74, no. 6, pp. 10721077, 2005.

[43] M. G. M. Alam, E. T. Snow, and A. Tanaka, "Arsenic and heavy metal contamination of vegetables grown in Samta village, Bangladesh," Science of the Total Environment, vol. 308, no. 1-3, pp. 83-96, 2003.

[44] G. Zurera, B. Estrada, F. Rincón, and R. Pozo, "Lead and cadmium contamination levels in edible vegetables," Bulletin of Environmental Contamination and Toxicology, vol. 38, no. 5, pp. 805-812, 1987.

[45] I. O. Akinyele and O. Osibanjo, "Levels of some trace elements in hospital diets," Food Chemistry, vol. 8, no. 4, pp. 247-251, 1982.

[46] M. Huang, S. Zhou, B. Sun, and Q. Zhao, "Heavy metals in wheat grain: Assessment of potential health risk for inhabitants in Kunshan, China," Science of the Total Environment, vol. 405, no. 1-3, pp. 54-61, 2008.

[47] Y.-J. Cui, Y.-G. Zhu, R.-H. Zhai et al., "Transfer of metals from soil to vegetables in an area near a smelter in Nanning, China," Environment International, vol. 30, no. 6, pp. 785-791, 2004.

[48] N. Zheng, Q. Wang, X. Zhang, D. Zheng, Z. Zhang, and S. Zhang, "Population health risk due to dietary intake of heavy metals in the industrial area of Huludao city, China," Science of the Total Environment, vol. 387, no. 1-3, pp. 96-104, 2007.

[49] Y. Chen, P. Wu, Y. Shao, and Y. Ying, "Health risk assessment of heavy metals in vegetables grown around battery production area," Scientia Agricola, vol. 71, no. 2, pp. 126-132, 2014.

[50] X. Wang, T. Sato, B. Xing, and S. Tao, "Health risks of heavy metals to the general public in Tianjin, China via consumption of vegetables and fish," Science of the Total Environment, vol. 350, no. 1-3, pp. 28-37, 2005.

[51] O. Akoto, F. Bismark Eshun, G. Darko, and E. Adei, "Concentrations and health risk assessments of heavy metals in fish from the Fosu Lagoon," International Journal of Environmental Research, vol. 8, no. 2, pp. 403-410, 2014. 

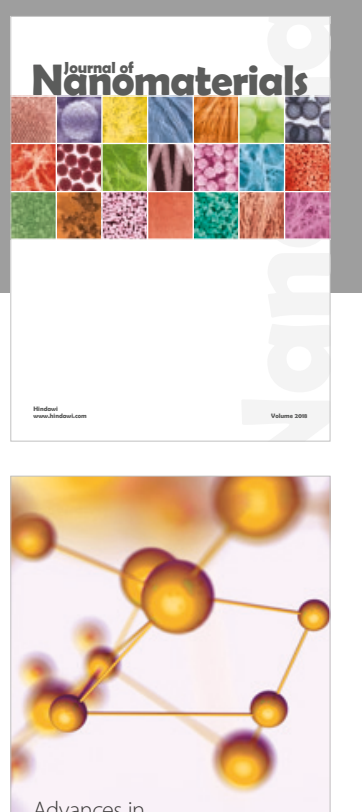

Physical Chemistry
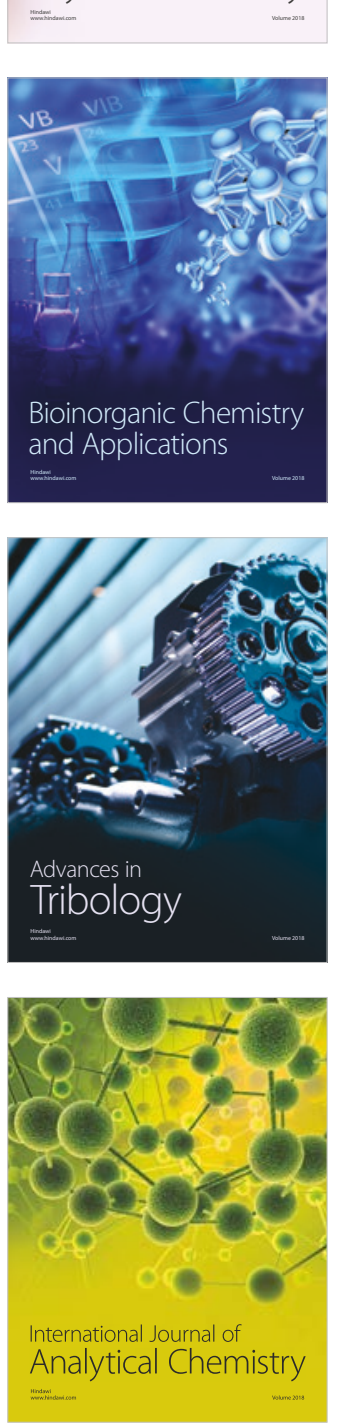

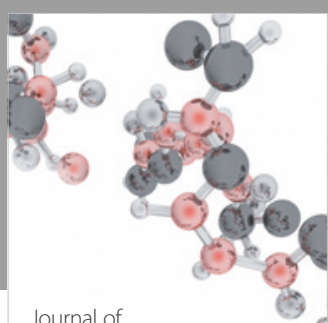

Analytical Methods

in Chemistry

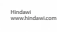

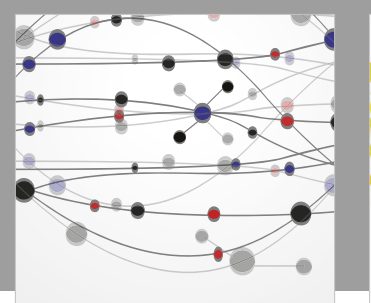

The Scientific World Journal

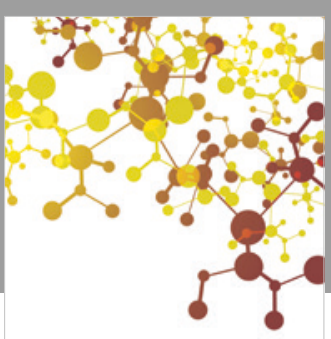

Journal of

Applied Chemistry
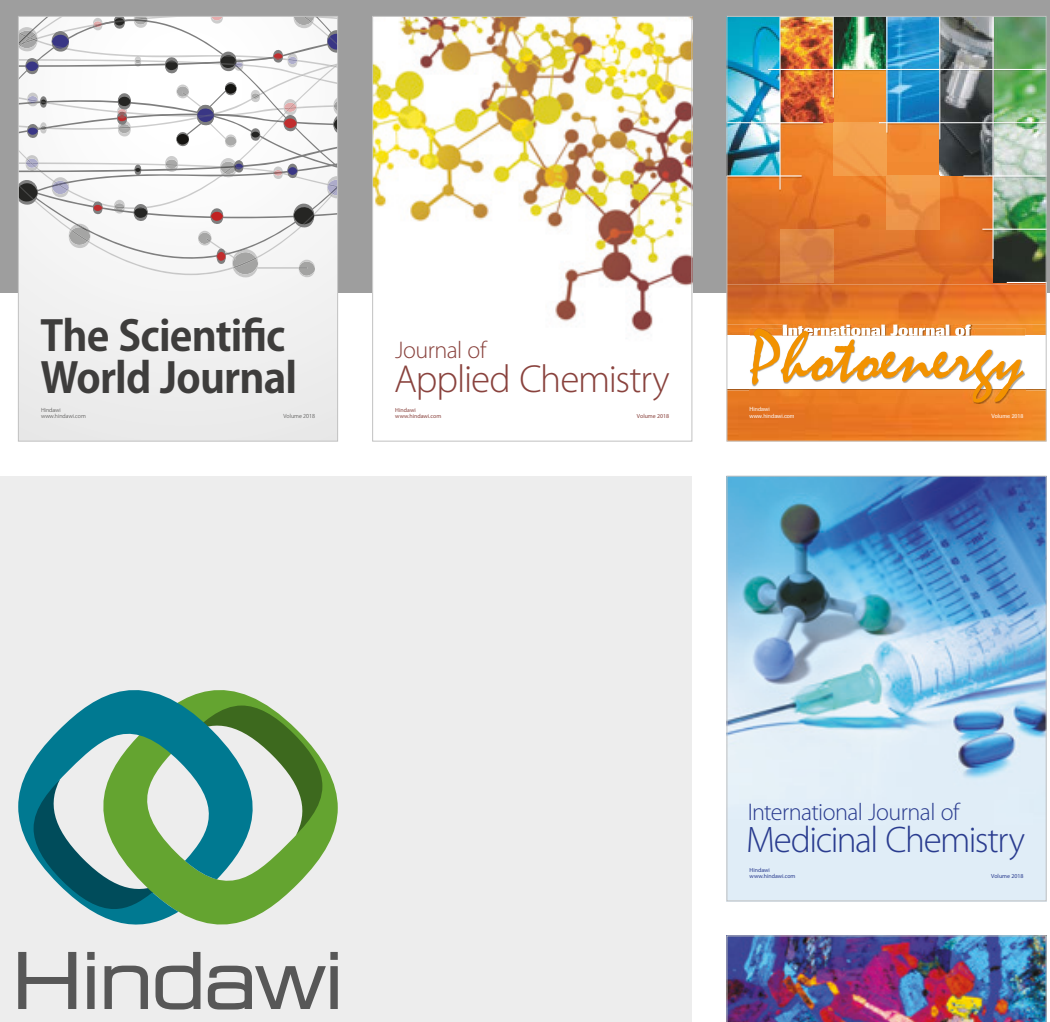

Submit your manuscripts at

www.hindawi.com
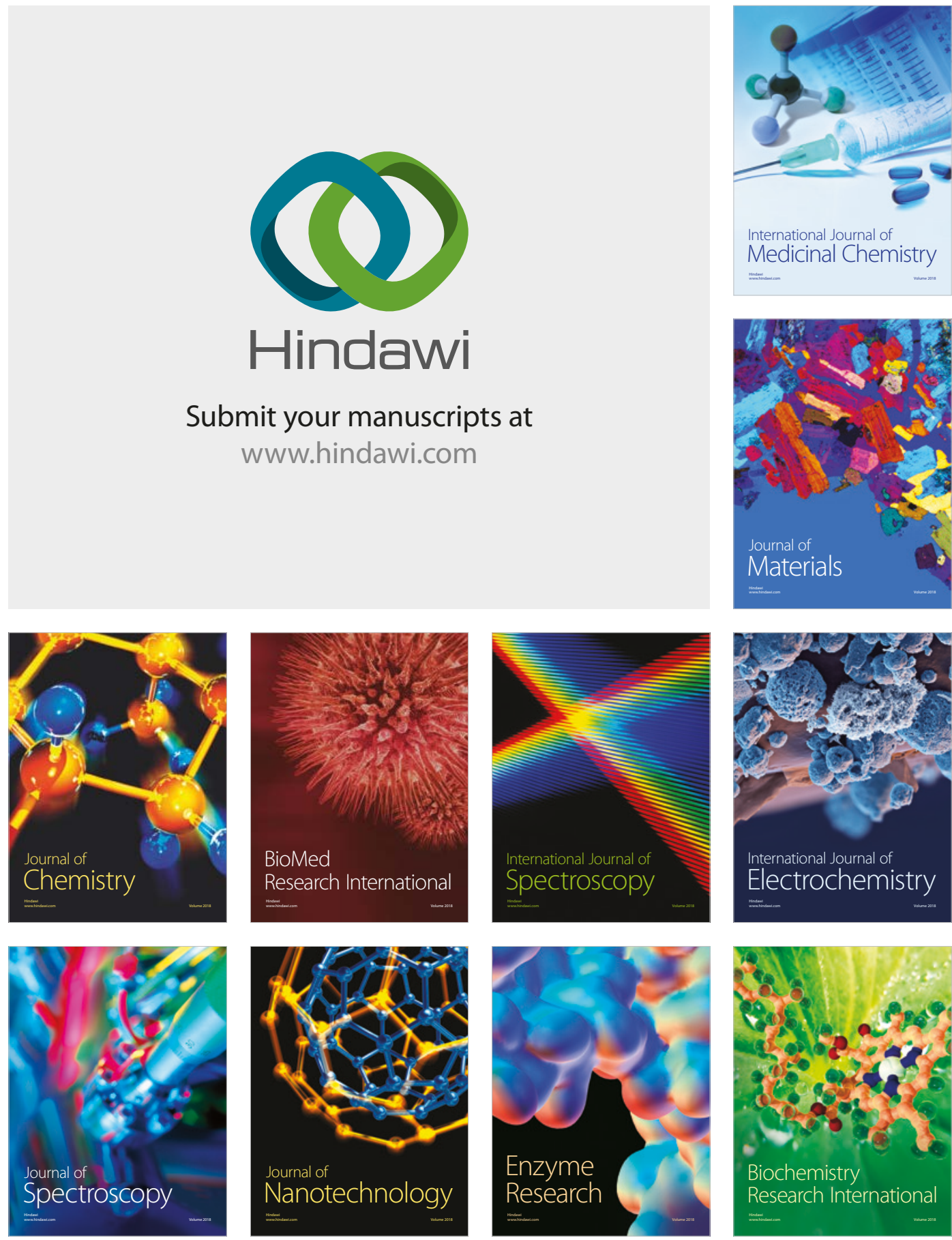
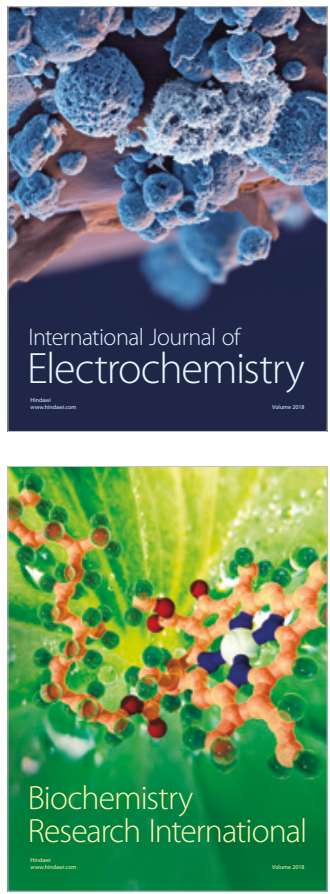